\title{
Engineering of Bi-/Mono-layer Graphene Film Using Reactive Ion Etching
}

\author{
M. Irannejad ${ }^{\dagger}$, W. Alyalak, S. Burzhuev, A. Brzezinski, and M. Yavuz \\ Waterloo Institute for Nanotechnology and Mechanical and Mechatronics Engineering, University of Waterloo, Waterloo \\ N2L 3G1, Canada \\ B. Cui \\ Waterloo Institute for Nanotechnology, University of Waterloo, Waterloo N2L 3G1, Canada
}

Received May 7, 2015; Revised May 19, 2015; Accepted July 22, 2015

\begin{abstract}
Although, there are several research studies on the engineering of the graphene layers using different etching techniques, there is not any comprehensive study on the effects of using different etching masks in the reactive ion etching (RIE) method on the quality and uniformity of the etched graphene films. This study investigated the effects of using polystyrene and conventional photolithography resist as a etching mask on the engineering of the number of graphene layers, using RIE. The effects were studied using Raman spectroscopy. This analysis indicated that the photo-resist mask is better than the polystyrene mask because of its lower post processing effects on the graphene surface during the RIE process. A single layer graphene was achieved from a bi-layer graphene after $3 \mathrm{~s}$ of the RIE process using oxygen plasma, and the bi-layer graphene was successfully etched after $6 \mathrm{~s}$ of the RIE process. The bilayer etching time was significantly smaller than reported values for graphene flakes in previous research.
\end{abstract}

Keywords: Graphene, Reactive ion etching, Raman spectroscopy

\section{INTRODUCTION}

In recent years, graphene, a $2 \mathrm{D}$ hexagonal structure of $\mathrm{sp}^{2}$ bonded carbon atoms [1] that are one atomic layer thick $(\sim 0.315$ $\mathrm{nm}$ ) [2]. Graphene has attracted significant attention from optoelectronics engineers and researchers in healthcare and medical engineering fields, because of its unique electrical, chemical, optical and mechanical properties and outstanding details in terms of its electronics band structure [1-4]. These remarkable properties of graphene offer an excellent material for a large number of different nanoelectronic and photonic applications, such as high speed transistors [5], biomechanical sensors [6], high frequency photodetectors [7] and saturable absorbers [8]. Although high

${ }^{\dagger}$ Author to whom all correspondence should be addressed: E-mail: Mehrdad.Irannejad@uwaterloo.ca

Copyright (C2015 KIEEME. All rights reserved.

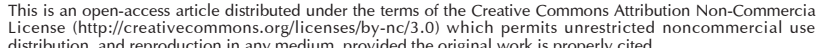
thense (nip) quality graphene films can be grown using epitaxial synthesis and chemical vapor deposition (CVD) [9-13], the fabrication of specific structures, such as graphene ribbons, graphene pads or graphene electrodes, still remain a challenge due to the engineering challenge of controlling the number of graphene layers in a multi-layered graphene film. The graphene based nanodecive performance can be significantly altered by the presence of fabrication residue [14]. Hence, the fabrication of the high quality and high uniformity of nanoscale structures using single/ bi-layer graphene is still a major challenge in advanced nanofabrication.

There are many ways to pattern nanostructures on graphene films. These ways include plasma etching [15], reactive ion etching [3], gas phase etching process [16], atomic layer etching [17] and electron beam photolithography $[18,19]$.

Oxygen plasma cleaning etch was usually used to remove the etching residue or graphene layers without controlling the number of layers that were being removed. Recently, Fabo et al. [3] used the oxygen plasma etching to remove one layer of graphene using poly(methyl methacrylate) (PMMA) as protect- 
ing layer. Single-layer graphene from bi-layer graphene sheets was achieved successfully through $17 \mathrm{~s}$ of etching the bi-layer graphene sample in an RIE system. The gas flow rate, radio frequency $(\mathrm{RF})$ power, and working pressure of the chamber were $10 \mathrm{sccm}, 70 \mathrm{~W}$ and 313 317 mTorr respectively. Although a monolayer graphene was achieved from the bi-layer graphene flakes, using long processing time could produce several defects on the graphene sheets, such as the reverse deposition of a carbon compound on the graphene sheet. This occurs through epoxy and carbonyl covalent bonds in the $\mathrm{sp}^{2}$ hybridization [20].

Prado et.al [14] employed the RIE process and plasma cleaning to remove the monolayer of graphene. Based on their observation the graphene layers can be etched using $\mathrm{O}_{2}$ or $\mathrm{Ar}$ as etchant gas. The optimum etching time of monolayer graphene was 15 $\mathrm{s}$ and $8 \mathrm{~min}$, respectively, by using RIE and plasma techniques and $\mathrm{Ar}$ as etchant gas. By using the $\mathrm{O}_{2}$ as the etchant gas, the optimum etching time was reported as $15 \mathrm{~s}$ and 3 min respectively for RIE and plasma techniques.

Although several studies have researched graphene layer engineering using different etching technique and different etchant gases, there has not been any research report that has comprehensively studied the effects of using different types of RIE etching masks on the quality of engineered graphene layers.

In this research, we compare the effects of using polystyrene (PS) and conventional photolithography resist (AZ 300) as protective materials on the number of layers engineered from the uniform graphene film using the RIE method.

\section{METHODOLOGY AND EXPERIMENT}

A series of bi-layer graphene films (grown on $\mathrm{SiO}_{2} / \mathrm{Si}$ substrate using CVD method, from ACS MATERIALS.) were coated with $200 \mathrm{~nm}$ of conventional positive AZ 300 photo-resist (PR) and 70 $\mathrm{nm}$ of polystyrene. The polystyrene solution was prepared by dispersing $2 \mathrm{wt} \%$ polystyrene (PS) latex particles (from Alfa Aesar) in $25 \mathrm{ml}$ of toluene. The etching mask was (i.e. PS or PR) deposited on the graphene film surface by means of a spin-casted method at a speed of 2,000 rpm for $40 \mathrm{~s}$ followed by three minutes of softbaking at $120^{\circ} \mathrm{C}$. The PR and PS films were patterned using contact mask-aligner (SUSS-MA6) as shown in Fig. 1(a) and Fig. 1(b). After an appropriate exposure time (i.e. $6 \mathrm{~s}$ ) and exposure power of $1 \mathrm{~mW} / \mathrm{cm}^{2}(\lambda=360 \mathrm{~nm})$, the developing process was carried out using MF319 and MIBK: IPA, 3:1, developer for $5 \mathrm{~s}$ and $10 \mathrm{~s}$, respectively, for samples with PR and PS masks. In the next step, samples were post baked to increase the adhesion and resilience of the protective materials to erosion during the RIE process as schematically depicted in Fig. (1).

The RIE experiments were carried out at a different etching time in the range of $3 \mathrm{~s}$ to $9 \mathrm{~s}$ using a commercial Phantom II Reactive Ion Etching system (Trion Technology Inc.). The processing parameters were fixed as: $\mathrm{O}_{2}$ (etchant gas) with a flow rate of $10 \mathrm{sccm}$ (standard cubic centimeters per minute unit), a working pressure of $200 \mathrm{mTorr}$ and an RF power density of $0.015 \mathrm{~W} /$ $\mathrm{cm}^{2}$ for both graphene films that were covered by conventional PR and PS polymers. The etching process parameters, such as etchant gas flow rate, RF power density and working pressure were optimized after a series of experiments based on the reported parameters in the literature $[3,9,14]$.

Raman spectroscopy is a powerful technique in characterizing the quality of the graphene films and investigating the number of layers $[21,22]$ in engineered graphene based devices. This technique is the more common and accurate characterization method in comparison to other techniques, such as atomic force microscopy (AFM) and optical microscopy. In a recorded Raman spectrum of graphene samples, the $\mathrm{I}_{2 \mathrm{D}} / \mathrm{I}_{\mathrm{G}}$ ratio is strongly cor-

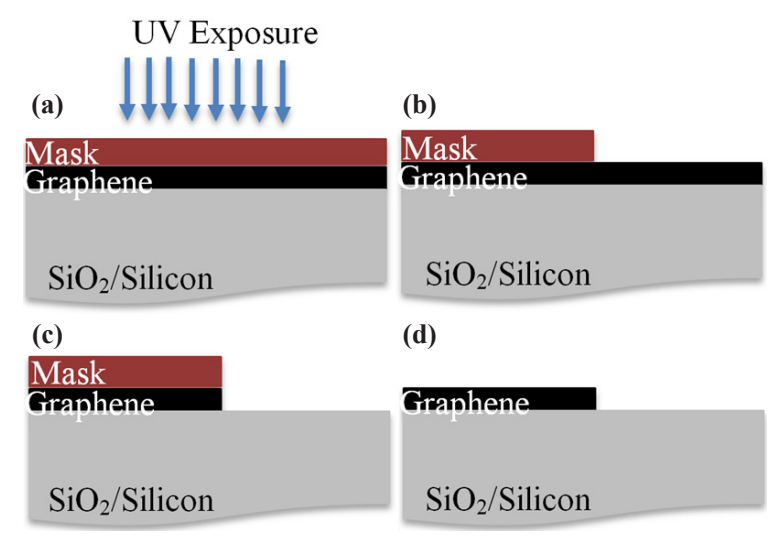

Fig. 1. Schematic diagram of graphene etching using a reactive ion etching technique, (a) photolithography, (b) developing, (c) after reactive ion etching, and (d) etched graphene.

related to the number of layers in the graphene sample [23]. In a monolayer graphene, this ratio is $I_{2 D} / I_{G}>2$, while for bi-layer graphene film the ratio is $1<\mathrm{I}_{2 \mathrm{D}} / \mathrm{I}_{\mathrm{G}}<2$ and, in the case of the multilayer graphene, it is $\mathrm{I}_{2 \mathrm{D}} / \mathrm{I}_{\mathrm{G}}<1$ [24]. Renishaw Raman spectrometer using an He-Ne laser ( $\lambda=632.8 \mathrm{~nm}$ and laser power of $20 \mathrm{~mW})$ as excitation source was employed to analysis the effects of different RIE processing times on engineering the graphene layer.

\section{RESULTS AND DISCUSSION}

The recorded Raman spectra of both graphene and the protected surfaces before the RIE process are shown in Fig. (2). The $\mathrm{I}_{2 \mathrm{D}} / \mathrm{I}_{\mathrm{G}}$ ratio and the full width at half maximum (FWHM) of the $2 \mathrm{D}$ band were calculated and compared in Table 1. From this table, it is clear that both covered and uncovered surfaces offer bi-layer graphene with a broad 2D band with FWHM in the range of between 27.65 and $34.50 \mathrm{~cm}^{-1}$. The effects of the chemical reaction and different molecular bond formations between the carbon atoms in the graphene structure and the PS were observed as a blue shift in the recorded Raman spectrum of the $2 \mathrm{D}$ band and seen to increase in the FWHM value as it is evident from Fig. 2(a). The calculated $\mathrm{I}_{2 \mathrm{D}} / \mathrm{I}_{\mathrm{G}}$ ratio and FWHM of $2 \mathrm{D}$ band values were reduced from 1.90 to 1.07 and from $34 \mathrm{~cm}^{-1}$ to 30.64 $\mathrm{cm}^{-1}$, respectively, as result of PS deposition of $70 \mathrm{~nm}$ on the graphene surface. Depositing $200 \mathrm{~nm}$ of PR on the graphene surface resulted in a red shift in the peak position and broadening of the $G$ band as indicated in Fig. 2(b). Small differences between the $\mathrm{I}_{2 \mathrm{D}} / \mathrm{I}_{\mathrm{G}}$ ratio of the two surfaces were recorded by covering the graphene surface with AZ300 as detailed in Table 1. The FWHM reduced from $32.83 \mathrm{~cm}^{-1}$ to $31.05 \mathrm{~cm}^{-1}$ by covering the graphene surface with PR; this is summarized in Table 1 . These reductions in the $\mathrm{I}_{2 \mathrm{D}} / \mathrm{I}_{\mathrm{G}}$ and the FWHM of the $2 \mathrm{D}$ band confirm more production of $\mathrm{sp}^{3}$ chemical bonds between the AZ300 polymeric chains and graphene surface.

Figure 3 shows the Raman spectrum of both unprotected and protected surfaces of graphene films covered by $70 \mathrm{~nm}$ of PS after different RIE processing times in the range of $3 \mathrm{~s}$ to $9 \mathrm{~s}$. As shown in Fig. 3(a) and detailed in Table 2, after 9 s of RIE the Raman spectroscopy still proposed a bilayer graphene. From this table it is evident that the $\mathrm{I}_{2 \mathrm{D}} / \mathrm{I}_{\mathrm{G}}$ ratio of the protected surface was varied between 1.22 and 1.52 during the RIE process, which is close to the ratios before the RIE process (Table 1). After $3 \mathrm{~s}$ of RIE, a single layer graphene film was achieved $\left(\mathrm{I}_{2 \mathrm{D}} / \mathrm{I}_{\mathrm{G}}=2.12\right)$ from the bi-layer graphene film. Increasing the RIE processing time to $6 \mathrm{~s}$ also offers a single layer graphene with higher $\mathrm{G}$ and D band 


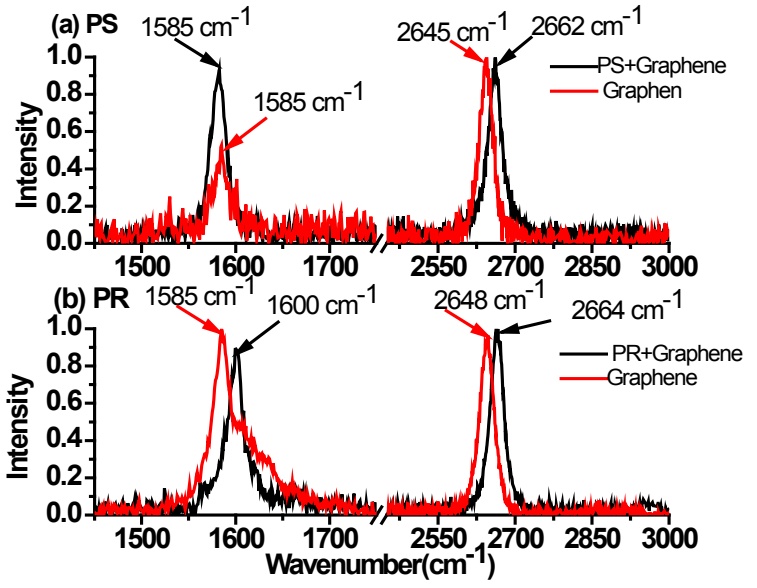

Fig. 2. Recorded Raman spectra of both graphene and protected surfaces by (a) polystyrene (PS) and (b) AZ300 photo-resist (PR) as an etching mask before the RIE process.

Table 1. The $\mathrm{I}_{2 \mathrm{D}} / \mathrm{I}_{\mathrm{G}}$ and FWHM values of both protected and unprotected surfaces before the RIE process. The excitation wavelength and laser power were fixed at $632.8 \mathrm{~nm}$ and $20 \mathrm{~mW}$, respectively.

\begin{tabular}{ccccc}
\hline & \multicolumn{2}{c}{ Photo-Resist } & \multicolumn{2}{c}{ Polystyrene } \\
\cline { 2 - 5 } & $\mathrm{I}_{2 \mathrm{D}} / \mathrm{I}_{\mathrm{G}}$ & $\mathrm{FWHM}\left(\mathrm{cm}^{-1}\right)$ & $\mathrm{I}_{2 \mathrm{D}} / \mathrm{I}_{\mathrm{G}}$ & $\mathrm{FWHM}\left(\mathrm{cm}^{-1}\right)$ \\
\hline \hline $\begin{array}{c}\text { Protected } \\
\text { surface }\end{array}$ & 1.08 & 31.05 & 1.07 & 30.64 \\
\hline $\begin{array}{c}\text { Graphene } \\
\text { surface }\end{array}$ & 1.01 & 32.83 & 1.90 & 34.10 \\
\hline
\end{tabular}
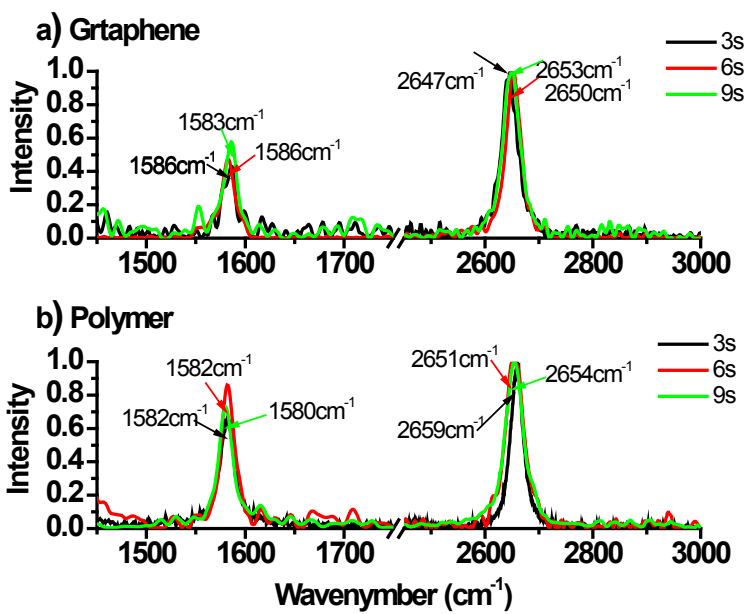

Fig. 3. Recorded Raman spectra of (a) graphene surface and (b) protected surface with $70 \mathrm{~nm}$ of PS after different RIE processing times in the range of $3 \mathrm{~s}$ to $9 \mathrm{~s}$.

intensity. Applying $9 \mathrm{~s}$ of RIE reduces the $\mathrm{I}_{2 \mathrm{D}} / \mathrm{I}_{\mathrm{G}}$ ratio from 2.02 to 1.54 .

As reported in Table 2, the calculated $\mathrm{I}_{2 \mathrm{D}} / \mathrm{I}_{\mathrm{G}}$ ratio of the graphene surface in the protected sample with PS was reduced from 2.02 to 1.54 after $9 \mathrm{~s}$ of the RIE process. This reduction in the calculated $\mathrm{I}_{2 \mathrm{D}} / \mathrm{I}_{\mathrm{G}}$ ratio could be attributed to the post-deposition of the etching residue from the mask on the graphene surface and protecting the surface from further etching through the molecular reaction between the carbon atoms in the graphene and the PS films. Hence, the calculated $\mathrm{I}_{2 \mathrm{D}} / \mathrm{I}_{\mathrm{G}}$ ratio was smaller after $9 \mathrm{~s}$ of
Table 2 . The $\mathrm{I}_{2 \mathrm{D}} / \mathrm{I}_{\mathrm{G}}$ ratio of both unprotected and protected graphene surfaces after different RIE processing times in the range of $3 \mathrm{~s}$ to 9 s. The excitation wavelength and laser power were fixed at $632.8 \mathrm{~nm}$ and $20 \mathrm{~mW}$, respectively.

\begin{tabular}{cccc}
\hline & $3 \mathrm{~s}$ & $6 \mathrm{~s}$ & $9 \mathrm{~s}$ \\
\hline PS & 1.52 & 1.22 & 1.30 \\
\hline Graphene & 2.12 & 2.02 & 1.54 \\
\hline PR & 1.22 & 1.03 & - \\
\hline Graphene & 2.14 & - & - \\
\hline
\end{tabular}
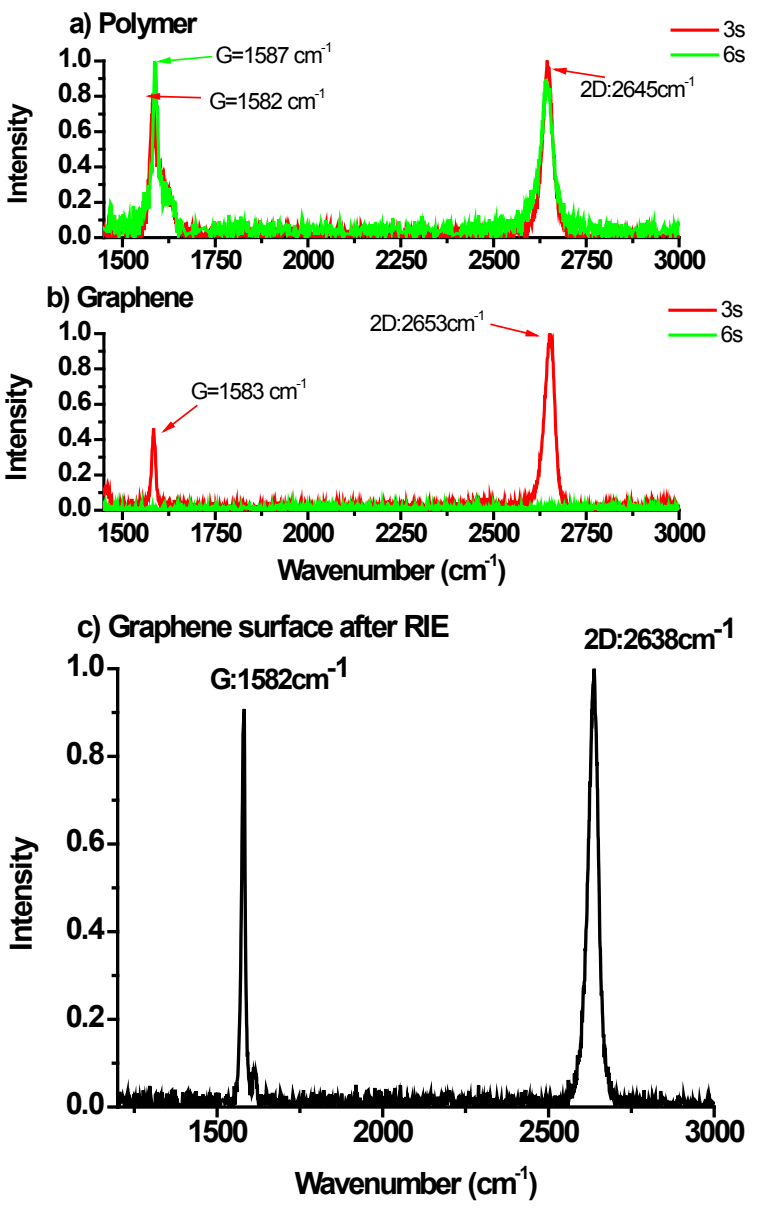

Fig. 4. The recorded Raman spectra of (a) covered graphene surface with AZ300 photo-resist, (b) graphene surface after $3 \mathrm{~s}$ and $6 \mathrm{~s}$ reactive ion etching, and (c) graphene surface after removing the photoresist etching mask.

etching than after $6 \mathrm{~s}$ of etching.

The Raman spectrum of both graphene and covered graphene surfaces with $200 \mathrm{~nm}$ of PR are compared in Fig. 4(a) and Fig. 4(b). As indicated in Fig. 4(a), no significant changes were recorded in the position of the $\mathrm{G}$ and $2 \mathrm{D}$ bands in the covered surface after $6 \mathrm{~s}$ of RIE. The $\mathrm{I}_{2 \mathrm{D}} / \mathrm{I}_{\mathrm{G}}$ ratio was calculated as 1.22 and 1.03 after $3 \mathrm{~s}$ and $6 \mathrm{~s}$ of RIE, respectively. These results are similar to the calculated ratio before the RIE process (i.e. $\mathrm{I}_{2 \mathrm{D}} / \mathrm{I}_{\mathrm{G}}=1.08$ ).

Figure 4(b) shows the Raman spectrum of the graphene surface before etching, after $3 \mathrm{~s}$ and after $6 \mathrm{~s}$ of RIE. The $2 \mathrm{D}$ and $\mathrm{G}$ bands were recorded at $2653 \mathrm{~cm}^{-1}$ and $1583 \mathrm{~cm}^{-1}$, respectively, and the $I_{2 D} / I_{G}$ was calculated as 2.14. In this figure, it is evident that after $6 \mathrm{~s}$ of RIE, the graphene was completely etched and there were no signs of the $\mathrm{G}$ and $2 \mathrm{D}$ bands in the recorded Raman spectrum. Figure 4(c) shows the recorded Raman spectrum 


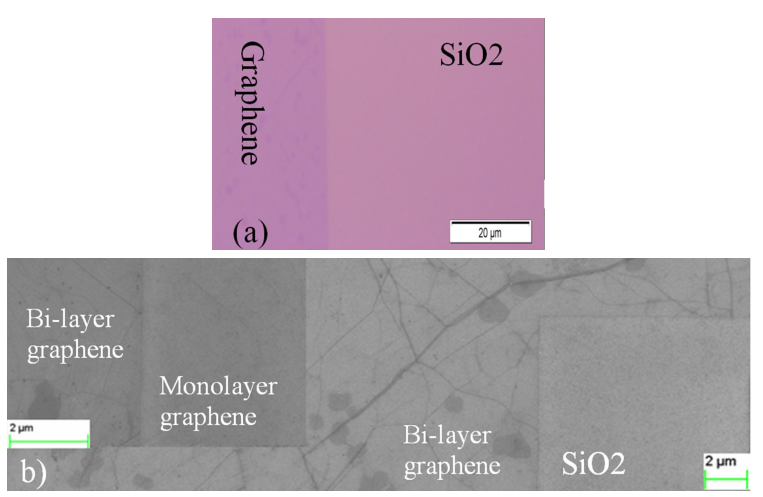

Fig. 5. (a) The optical and (b) SEM images of the bilayer graphene film etched using $6 \mathrm{~s}$ of the RIE process. The inset SEM shows the monolayer graphene after $3 \mathrm{~s}$ of the RIE process.

of the graphene surfaces after removing the etching mask (PR). The I2D/ IG ratio was calculated as 1.10. As shown in Fig. 4(c), no significant changes in the Raman spectrum of the graphene surface were recorded after the RIE process and the removal of the PR mask. Figure 5(a) and 5(b) show optical and SEM images of etched bi-layer graphene samples after $6 \mathrm{~s}$. The inset SEM image shows the monolayer graphene etched film after $3 \mathrm{~s}$ of the RIE process. As shown in Fig. 5(b), there was no etching residue after $6 \mathrm{~s}$ of the RIE process on the bi-layer graphene film on using the PR etching mask.

As can be concluded from Table 2 and Figs. 4(c) and 5, the reaction between the PR etching residue and the graphene surface after $6 \mathrm{~s}$ of RIE is less than the reaction when using PS as an etching mask.

\section{CONCLUSIONS}

This research studied the effects of using two different etching masks, photo-resist and polystyrene on the engineering of graphene layers. The study found that the photo-resist mask is more resistant than the polystyrene masks during the etching process and it produces lower post effects, such as post deposition of etching residue on the graphene surface. Achieving single layer graphene was confirmed by Raman spectroscopy after $6 \mathrm{~s}$ of the RIE process and using the oxygen at a flow rate of $10 \mathrm{sccm}$, RF power density of $0.0015 \mathrm{~W} / \mathrm{cm}^{2}$ and working pressure of 200 mTorr. In this study, the achieved etching time for a single layer graphene film grown by CVD was significantly smaller than reported values (15 s) for a graphene flake [14].

\section{REFERENCES}

[1] T. Tsukamoto and T. Ogino, The Journal of Physical Chemistry C, 115, 8580 2011. [DOI: http://dx.doi.org/10.1021/jp1094933]

[2] M. C. Lemme, D. C. Bell, J. R. Williams, L. A. Stern, B.W.H Baugher, P. Jarillo-Herrero, and C. M. Marcus, ACS Nano, 3, 2674 (2009). [DOI: http://dx.doi.org/10.1021/nn900744z]

[3] R. Fubo, L. Wen, and D. Lixin, Layer Engineering of Graphene with Oxygen Plasma Etching, Nanotechnology (IEEE-NANO),
2011 11th IEEE Conference on 2011.

[4] A. K. Geim and K. S. Novoselov, Nat Mater., 6, 183 (2007). http:// dx.doi.org/10.1038/nmat1849]

[5] F. Schwierz, Nat Nano, 5, 487 (2010). http://dx.doi.org/10.1038/ nnano.2010.89]

[6] Z. Li, M. He, D. Xu, and Z. Liu, Journal of Photochemistry and Photobiology C: Photochemistry Reviews, 18, 1 (2014). [DOI: http://dx.doi.org/10.1016/j.jphotochemrev.2013.10.002]

[7] T. Mueller, F. Xia, and P. Avouris, Nat. Photon., 4, 297 (2010). http://dx.doi.org/10.1038/nphoton.2010.40]

[8] G. Q. Xie, J. Ma, P. Lv, W. L. Gao, P. Yuan, L. J. Qian, H. H. Yu, H. J. Zhang, J. Y. Wang, and D. Y. Tang, Optical Materials Express, 2, 878 (2012). [DOI: http://dx.doi.org/10.1364/OME.2.000878]

[9] A. M. Haider, R. Fubo, L. Wen, and D. Lixin, Nano-Micro Letters, 6, 116 (2014). [DOI: http://dx.doi.org/10.1007/BF03353775]

[10] B. Sanyal and O. Eriksson, Advanced Functional Materials: A Perspective from Theory and Experiment (Elsevier, 2012)

[11] X. Li, W. Cai, J. An, S. Kim, J. Nah, D. Yang, R. Piner, A. Velamakanni, I. Jung, E. Tutuc, S. K. Banerjee, L. Colombo, and R. S. Ruoff, Science, 324, 1312 (2009). [DOI: http://dx.doi. org/10.1126/science.1171245]

[12] D. Wei, Y. Liu, Y. Wang, H. Zhang, L. Huang, and G. Yu, Nano Letters, 9, 1752 (2009). [DOI: http://dx.doi.org/10.1021/nl803279t]

[13] A. Reina, X. Jia, J. Ho, D. Nezich, H. Son, V. Bulovic, M. S. Dresselhaus, and J. Kong, Nano Letters, 9, 30 (2008). [DOI: http:// dx.doi.org/10.1021/nl801827v]

[14] M. C. Prado, D. Jariwala, T. J. Marks, and M. C. Hersam, Applied Physics Letters, 102 (2013).

[15] C. Isaac, A. J. Luis, T. Jifa, and P. C. Yong, New Journal of Physics, 13, 025008 (2011). [DOI: http://dx.doi.org/10.1088/1367$2630 / 13 / 2 / 025008]$

[16] X. Wang and H. Dai, Nat. Chem., 2, 661 (2010). http://dx.doi. org/10.1038/nchem.719]

[17] W. S. Lim, Y. Y. Kim, H. Kim, S. Jang, N. Kwon, B. J. Park, J. H. Ahn, I. Chung, B. H. Hong, and G. Y. Yeom, Carbon, 50, 429 (2012). [DOI: http://dx.doi.org/10.1016/j.carbon.2011.08.058]

[18] S. C. Jeon, Y. S. Kim, and D. K. Lee, Trans. Electr. Electron. Mater., 11, 190 (2010). [DOI: http://dx.doi.org/10.4313/ TEEM.2010.11.3.145]

[19] P. L. Neumann, E. Tóvári, S. Csonka, K. Kamarás, Z. E. Horváth, and L. P. Biró, Nuclear Instruments and Methods in Physics Research Section B: Beam Interactions with Materials and Atoms, 282, 130 (2012). [DOI: http://dx.doi.org/10.1016/ j.nimb.2011.08.044]

[20] J. R. Rani, J. Lim, J. Oh, J. W. Kim, H. S. Shin, J. H. Kim, S. Lee, and S. C. Jun, The Journal of Physical Chemistry C, 116, 19010 (2012). [DOI: http://dx.doi.org/10.1021/jp3050302]

[21] M. Ferreira, E. H., M.V.O. Moutinho, F. Stavale, M. M. Lucchese, R. B. Capaz, C. A. Achete, and A. Jorio, Physical Review $B$, 82, 125429 (2010). [DOI: http://dx.doi.org/10.1103/PhysRevB.82.125429]

[22] C.N.R. Rao and A. K. Sood, Graphene: Synthesis, Properties, and Phenomena (Wiley, 2013)]

[23] K. S. Subrahmanyam, L. S. Panchakarla, A. Govindaraj, and C.N.R. Rao, The Journal of Physical Chemistry C, 113, 4257 (2009). [DOI: http://dx.doi.org/10.1021/jp900791y]

[24] Z. Tu, Z. Liu, Y. Li, F. Yang, L. Zhang, Z. Zhao, C. Xu, S. Wu, H. Liu, H. Yang, and P. Richard, Carbon, 73, 252 (2014). [DOI: http:// dx.doi.org/10.1016/j.carbon.2014.02.061] 